\title{
Do the Microbiota Influence Vaccines and Protective Immunity to Pathogens?
}

\section{If So, Is There Potential for Efficacious Microbiota-Based Vaccines?}

\author{
Dan R. Littman ${ }^{1,2}$ \\ ${ }^{1}$ Kimmel Center for Biology and Medicine of the Skirball Institute, New York University School of Medicine, \\ New York, New York 10016 \\ ${ }^{2}$ The Howard Hughes Medical Institute, New York University School of Medicine, New York, New York 10016 \\ Correspondence: dan.littman@med.nyu.edu
}

\begin{abstract}
The gut-resident constituents of the microbiota protect the mucosa from invasive pathogens through engagement of both innate and adaptive branches of the immune system. They are also likely to provide systemic protection from pathogens, by enhancing host robustness and tolerance to the invasive microbes and by inducing immune responses that prevent their growth. These properties of commensal microbiota, particularly the capacity of some bacteria to induce diverse types of antigen-specific immune responses, raises the prospect that they could be deployed as vaccine vectors to generate effective local and systemic immunity to viral and bacterial pathogens.
\end{abstract}

\section{GREAT DEBATES}

What are the most interesting topics likely to come up over dinner or drinks with your colleagues? Or, more importantly, what are the topics that don't come up because they are a little too controversial? In Immune Memory and Vaccines: Great Debates, Editors Rafi Ahmed and Shane Crotty have put together a collection of articles on such questions, written by thought leaders in these fields, with the freedom to talk about the issues as they see fit. This short, innovative format aims to bring a fresh perspective by encouraging authors to be opinionated, focus on what is most interesting and current, and avoid restating introductory material covered in many other reviews.

The Editors posed 13 interesting questions critical for our understanding of vaccines and immune memory to a broad group of experts in the field. In each case, several different perspectives are provided. Note that while each author knew that there were additional scientists addressing the same question, they did not know who these authors were, which ensured the independence of the opinions and perspectives expressed in each article. Our hope is that readers enjoy these articles and that they trigger many more conversations on these important topics.

Editors: Shane Crotty and Rafi Ahmed

Additional Perspectives on Immune Memory and Vaccines: Great Debates available at www.cshperspectives.org

Copyright (C) 2018 Cold Spring Harbor Laboratory Press; all rights reserved; doi: 10.1101/cshperspect.a029355

Cite this article as Cold Spring Harb Perspect Biol 2018;10:a029355 
D.R. Littman

It has long been known that the commensal microbiota contributes to development and priming of immune system cells. During the past decade, there have been major advances in our understanding of how gut-resident microbes communicate with both innate and adaptive arms of the immune system (Hooper et al. 2012). Much of the dialogue ensures that commensal species can replicate within their niches without causing harm to the host (Ayres 2016). This process of host tolerance to microbes often provides the added benefit of resistance to pathogens, providing a first line of innate defense until adaptive responses can be mustered to clear the offending organisms. For example, commensal microbes in the gut induce innate lymphoid cells to produce interleukin (IL)-22, which, in turn, promotes barrier function through epithelial cell regeneration and production of antimicrobial peptides, limiting attachment and growth of adherent-invasive Escherichia coli or Citrobacter rodentium (Fig. 1) (Sonnenberg et al. 2011; Hooper et al. 2012; Longman et al. 2014). Commensal microbes also induce $\mathrm{B}$ - and $\mathrm{T}$-cell responses that regulate the levels of different microbial constituents, either through direct interactions (e.g., by way of opsonized secreted IgA or T-cell killing of infected cells) or, indirectly, by antigen-specific responses that engage downstream innate effector functions (e.g., recruitment of neutrophils that kill pathogenic and nonpathogenic organisms) (Fig. 1) (Honda and Littman 2016). Engagement of both innate and adaptive immune responses by microbiota offers the potential for utilizing individual bacterial species or consortia of select strains to develop microbiome-based vaccination strategies. In this article, I will speculate on how the microbiota may provide protection from pathogenic microbes and will propose applications toward infection control.

\section{INTESTINAL BACTERIAL CROSS TALK WITH THE HOST IMMUNE SYSTEM}

It is currently thought that only a small subset of gut-resident bacteria has direct influence on the immune system. Many of these bacteria can readily be identified because they are coated with IgA or IgG. These are likely bacterial species that can be engaged by the antigen presentation machinery in the lamina propria, after which they elicit diverse T-cell response programs. Flavell and colleagues showed that mice colonized with IgA-coated bacteria from inflammatory bowel disease patients are rendered sensitive to chemically induced colitis (Palm et al. 2014). However, the $\operatorname{IgA}^{+}$fraction of bacteria from healthy donors did not have such propensity. Similarly, the $\operatorname{IgA}^{+}$microbiota from undernourished children was enriched for IgA-coated species (particularly Enterobacteriaceae) that were colitogenic in gnotobiotic mice, but the $\operatorname{IgA}^{+}$fraction from healthy control donors was largely protective (Kau et al. 2015). These results are consistent with the notion that gut bacteria can elicit diverse immune responses, and indicate that their ability to induce bacteria-specific IgA does not need to reflect either pro- and anti-inflammatory barrier immune responses.

It is becoming appreciated that commensal microbes induce dominant $\mathrm{T}_{\mathrm{H}} 1, \mathrm{~T}_{\mathrm{H}} 17$, or Tregcell responses in gut-associated mucosal tissues. In skin, CD8 T-cell responses are elicited by Staphylococcus epidermidis and, while similar responses have not been investigated in detail in the intestine, they clearly do exist, as shown recently in mice colonized with microbiota from pet store animals rather than from mice in specific pathogen-free facilities (Naik et al. 2015; Beura et al. 2016). In addition, some bacteria and helminths induce distinct cytokine responses by epithelial and myeloid cell subsets, resulting in activation of distinct subsets of innate lymphoid cells (Sano et al. 2015; Howitt et al. 2016). Together, these responses contribute not only to local barrier enforcement or wound healing, but also to systemic immune system modulation that can have either beneficial or detrimental outcomes. For example, bacteria that induce local production of IL-22 by type 3 innate lymphoid cells (ILC3) and the differentiation of $\mathrm{T}_{\mathrm{H}} 17$ cells have important roles in protection of mucosal surfaces from pathogenic invasive microbes, but in some settings can provoke local or systemic autoimmune disease (Honda and Littman 2016). 
Do the Microbiota Influence Vaccines and Protective Immunity to Pathogens?

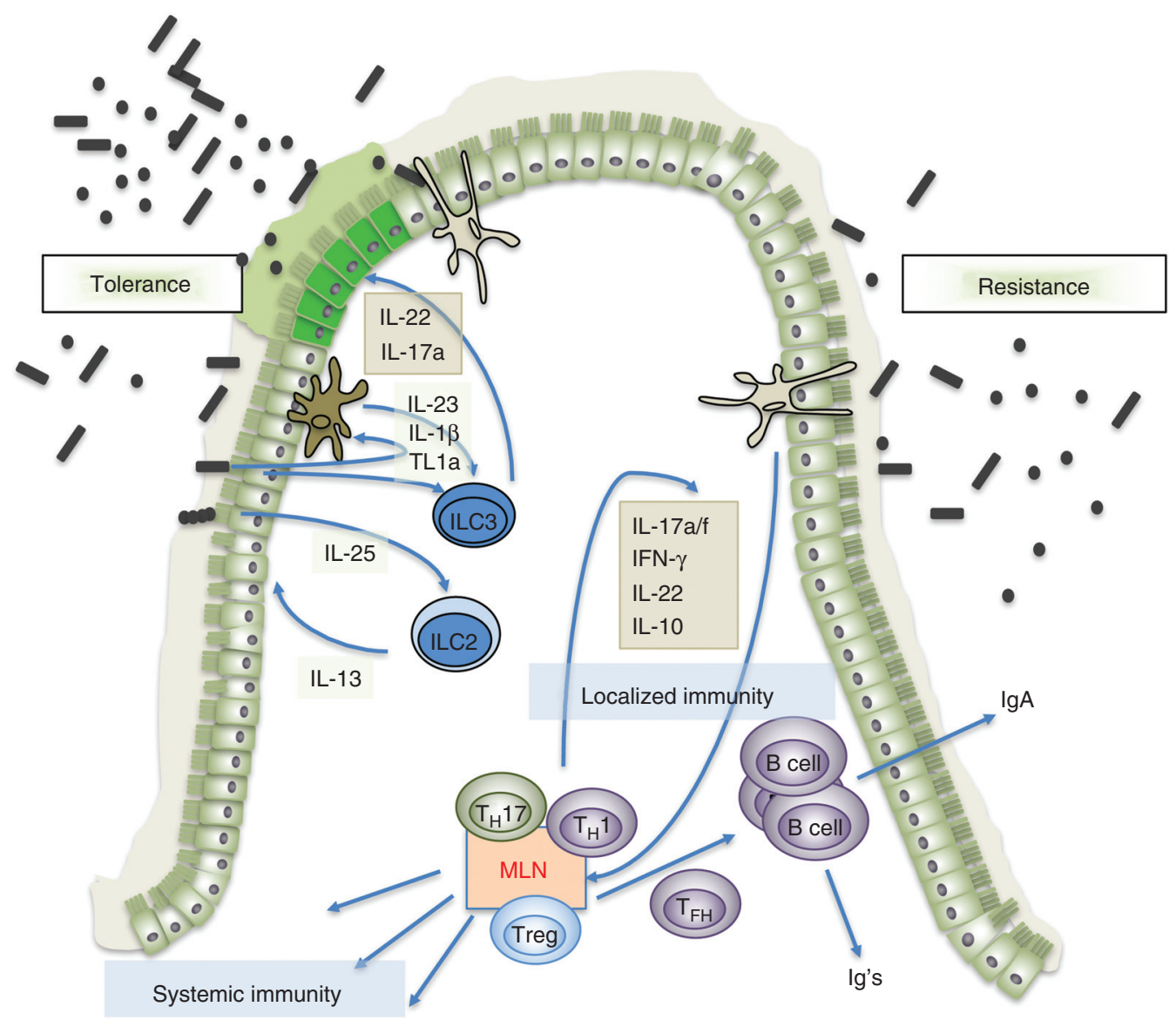

Figure 1. Microbiota-mediated strategies for host-mediated protection from pathogens. (Left) Tolerance induced by microbiota by way of innate signals mediated by epithelial cells, myeloid cells, and innate lymphoid cells. Cytokines and growth factors produced by cells such as ILC3 result in more robust epithelial barrier function and modifications in the mucin layer (e.g., allowing pathogenic bacteria to forage fucose, precluding invasion of host tissues despite high bacterial load). ILC2 may also participate in promoting tolerance, by responding to microbeinduced epithelial tuft cell-produced interleukin (IL)-25 with secretion of IL-13, which promotes epithelial robustness. (Right) Resistance to pathogenic bacteria through induction of microbiota-specific T- and B-cell responses. Myeloid cells (macrophages/dendritic cells) take up microbial products, transport them to draining lymph nodes (mesenteric lymph node $[\mathrm{MLN}]$ ), and present microbiota antigen to naïve T cells, activating them and polarizing them (CD8 T cells are not depicted, but are likely also primed). The $\mathrm{T}$ cells then distribute throughout the body, including the intestinal lamina propria, and limit microbial growth through production of cytokines and recruitment of neutrophils and other phagocytic cells. The $\mathrm{T}$ cells also differentiate into follicular helper $\mathrm{T}$ cells $\left(\mathrm{T}_{\mathrm{FH}}\right)$, which promote $\mathrm{B}$-cell affinity maturation and isotype class switching, with production of secreted IgA and other classes of antibody (Ig) that can function systemically. IFN, Interferon.

The best-known and clinically validated example of microbiome-based therapy to protect from a pathogen is fecal microbiome transfer (FMT) for Clostribium difficile-mediated colitis. Pamer and colleagues used a mouse model for $C$. difficile pathogenesis to show that
Clostridial species (e.g., Clostridium scindens), endowed with enzymatic capacity to modify primary bile acids (i.e., bile salt hydrolases), can prevent germination of $C$. difficile spores and thus reduce its vegetative growth. Whether this is the active principle of FMT remains to be 


\section{D.R. Littman}

determined and, indeed, intestinal epithelial cell-derived antimicrobial peptides, induced by ILC3-derived IL-22, as well as interferon $\gamma$ (IFN- $\gamma$ )-producing ILC1 may also have critical roles in restraining $C$. difficile growth (Abt et al. 2015). Modulation of the host immune response may have an influence in therapeutic efficacy of probiotics in blooms of $C$. difficile and other pathogenic bacteria, such as vancomycin-resistant enterococcus and antibioticresistant Klebsiella pneumoniae, but mechanisms of action have not been elucidated. A detailed discussion of probiotic therapies that induce colonization resistance through different mechanisms is found in a recent review (Pamer 2016).

Studies that specifically examined microbiota effects on pathogenic microbes have largely been confined to proximal interactions that can involve competition between microbes, as postulated for $C$. difficile control, activation of host-tolerance mechanisms, or activation of immune pathways that can contribute to resistance to the infectious agent. Examples of how microbiota induce tolerance to specific pathogens are scarce, and are largely confined to model systems. For example, a recent publication described how a peptidoglycan hydrolase produced by the commensal Enterococcus faecium can activate host cells to tolerate infection with Salmonella both in Caenorhabditis elegans and in mice (Rangan et al. 2016). This tolerance to high levels of pathogenic microbes was proposed to be the result of enhanced barrier integrity, which would likely provide protection from multiple invasive microbes (Fig. 1). This type of microbiota-triggered host-defense mechanism seems most likely to be effective at mucosal surfaces, where high titers of potentially pathogenic microbes can be sustained with minimal damage to the host. Microbiota-mediated tolerance has also been proposed to extend beyond intestinal niches, as a mouse commensal with invasive potential was found to protect animals from muscle wasting following systemic infection with pathogenic bacteria (Schieber et al.2015). Tolerance is often mediated through activation of innate immune pathways (e.g., inflammasome or Toll-like receptor activation and production of cytokines such as IL-22) that reinforce epithelial barriers and/or provide a source of nutrients, such as fucose, to foraging bacteria (Ayres 2016).

\section{HARNESSING ADAPTIVE IMMUNE RESPONSES TO PROTECT FROM PATHOGENS}

Although mechanistic characterization of commensal microbe-guided immune responses is in its infancy, it is becoming clear that microbial antigen-specific responses can be matched to effector functions of the responding cells. This feature of microbiota-dependent immune modulation may be amenable to manipulation for therapeutic or prophylactic vaccination to provide immunity to pathogens, for enhancing antitumor immunity, or for reducing autoinflammatory responses.

In contrast to innate responses that contribute to tolerance, resistance to pathogens by way of their targeting and elimination is most effectively achieved through adaptive immune responses. These are expected to target antigenic epitopes encoded by the immunogenic species and, potentially, by related pathogenic species. Recent studies have shown that select commensal bacteria induce polarized $\mathrm{CD} 4^{+}$ $\mathrm{T}$-cell responses directed at antigen encoded by those bacteria. Thus, segmented filamentous bacteria (SFB) induces $\mathrm{T}_{\mathrm{H}} 17$ cells with specificity for major histocompatibility complex (MHC) class II and SFB antigen (Yang et al. 2014). Other intestinal bacteria can induce $\mathrm{T}_{\mathrm{H}} 1$ or Treg cell polarization, and those $\mathrm{T}$ cells are likewise specific for the inducing bacterial antigens. For example, colonic Treg cells induced by Helicobacter hepaticus recognize peptides generated from the bacterium's proteins (H Xu and DR Littman, unpubl.). In addition, the same bacteria that induce these antigen-specific polarized $\mathrm{T}$-cell responses also induce follicular helper cells that contribute to production of bacteria-specific secretory IgA as well as other immunoglobulins (Fig. 1). It is not yet known whether the $\mathrm{T}_{\mathrm{FH}}$ cells elicited by different bacteria at diverse sites along the gastrointestinal (GI) tract have unique properties, but with the 


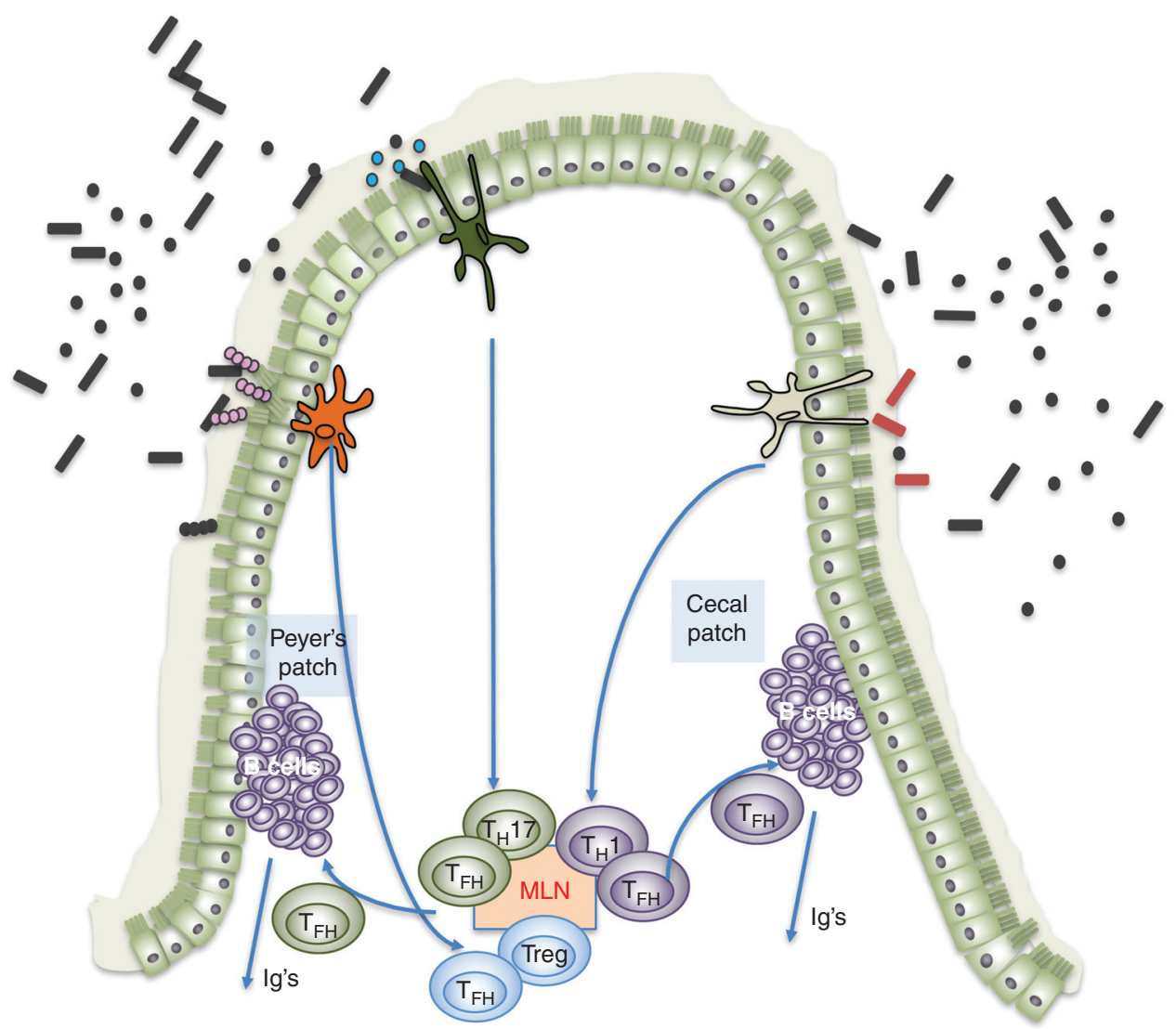

Figure 2. Microbiota-dependent follicular helper cell-mediated antibody diversification. Model for how individual commensal species may induce different types of $\mathrm{CD} 4^{+} \mathrm{T}$ cells, including follicular helper $\mathrm{T}$ cells $\left(\mathrm{T}_{\mathrm{FH}}\right)$ that elicit distinct types of antibody responses. Microbe-specific T cells could potentially be engaged to provide tailored signals to follicular B cells in gut-associated lymphoid tissues, resulting in enhanced diversification and selective isotype switching. This could be effective in conjunction with vaccination to enhance antiviral and antitumor antibody responses. Additionally, bacteria engineered to express tumor neoantigens could be used as vaccines to induce antigen-specific $\mathrm{T}_{\mathrm{H}}$ cells with desired cytokine profiles (e.g., $\mathrm{T}_{\mathrm{H}} 1$ ) for tumor immunotherapy. MLN, Mesenteric lymph node.

currently available tools it is now possible to study such cells and determine their influence on B-cell diversification. Optimization of $\mathrm{T}_{\mathrm{FH}}$ function could have an impact on vaccine design, potentially allowing for enhanced immunoglobulin gene somatic hypermutation and/ or directed isotype switching. This could be especially valuable for control of viral infections by eliciting broadly neutralizing antibodies (Doria-Rose and Joyce 2015).

Antibodies that neutralize HIV by targeting conserved epitopes of the viral envelope glycoprotein require numerous rounds of somatic hypermutation. While such antibodies can be detected in infected individuals, they are relatively rare and appear late in the course of disease. Vaccines that incorporate T-cell epitopes encoded by select commensal bacteria that promote $\mathrm{T}_{\mathrm{FH}}$ differentiation could potentially accelerate affinity maturation, and may thus be efficacious in therapeutic and prophylactic applications (Fig. 2).

The coevolution of host and microbiome raises the possibility that some commensals are selected for their propensity to elicit tolerance mechanisms and/or specialized immune 


\section{D.R. Littman}

responses that protect the host from diverse pathogens. Such a protective immune response may indeed be carried out by cells designated as $\mathrm{T}_{\mathrm{H}} 1^{*}$, which have been described as having properties of both $\mathrm{T}_{\mathrm{H}} 1$ and $\mathrm{T}_{\mathrm{H}} 17$ cells (Sallusto 2016). These cells produce IFN- $\gamma$ but, unlike $\mathrm{T}_{\mathrm{H}} 1$ cells that express the chemokine receptor CXCR3, they additionally express CCR6, which is regulated by the $\mathrm{T}_{\mathrm{H}} 17$-cell transcription factor ROR yt. Most tellingly, patients with homozygous null mutations in RORC are highly susceptible to Mycobacterium tuberculosis, and cannot control bacterial growth after immunization with bacillus Calmette-Guérin (BCG), an attenuated strain of Mycobacterium bovis. Such individuals appear to have normal $\mathrm{T}_{\mathrm{H}} 1$ responses to viruses, but are also susceptible to opportunistic Candida albicans, which is controlled by $\mathrm{T}_{\mathrm{H}} 17$ cells (Okada et al. 2015). $\mathrm{T}_{\mathrm{H}} 17$ cells induced by bacteria such as SFB do not produce IFN- $\gamma$ and are thought to protect epithelial barriers but to be generally noninflammatory. In contrast, IL-23R/ROR $\gamma$ t-dependent "pathogenic" $\mathrm{T}_{\mathrm{H}} 17$ cells, potentially the mouse equivalent of human $\mathrm{T}_{\mathrm{H}} 1^{*}$ cells, produce various combinations of IL-17, IFN- $\gamma$, and granulocyte-macrophage colony-stimulating factor (GM-CSF) and have been implicated in multiple autoimmune diseases (Hirota et al. 2011). It is not yet known whether there are distinct constituents of the microbiota that induce such cells under homeostatic conditions. However, in the context of proinflammatory conditions, as observed following a blockade of IL-10 signaling, distinct bacterial species guide the differentiation of "pathogenic" $\mathrm{T}_{\mathrm{H}} 17$ cells that contribute to inflammatory bowel disease (Ahern et al. 2010). It has also been shown that $T_{H} 17$ cells induced by gut bacteria can function systemically in promoting autoimmune diseases, including a spontaneous model of arthritis and myelin protein-induced experimental autoimmune encephalomyelitis (Wu et al. 2010; Lee et al. 2011). Treg cells induced in the large intestine by colonization with a consortium of Clostridial species have likewise been shown to restrain systemic inflammatory processes (Atarashi et al. 2013). These findings suggest that it may be possible to engineer specific bacterial strains endowed with desired inductive functions to serve as vaccine vectors. The $\mathrm{T}$ cells would be primed in the intestinal mucosaassociated lymphoid tissues, most likely the mesenteric lymph nodes, and could then exert their protective functions either in the gut or elsewhere. SFB-specific T cells induced by the colonizing bacteria can be found disseminated in lymphoid organs distal to the intestine, which is consistent with the notion that priming of microbiota-specific $\mathrm{T}$ cells in the gut mucosa can contribute to systemic immunity. Whether such primed $\mathrm{T}$ cells can also take up residence in tissues distal to the gut, where they could exert long-term protective functions, has not been determined.

\section{CONCLUDING REMARKS}

The commensal microbiota's influence on quality and quantity of innate and adaptive immune responses and its role in protection from invasive pathogens suggests that it will have a place in design of future therapeutic and prophylactic vaccines. However, the success of such approaches will require a much deeper mechanistic understanding of how individual microbes or defined communities achieve their effect. The key parameters for the establishment of durable antigen-specific responses will need to be characterized in animal models, potentially with human microbiota constituents. As there is growing evidence that the microbiota contributes to immune control of tumors, select microbes could potentially also be used to deliver neoantigens in vaccination strategies aimed at targeting tumor cells or the tumor microenvironment (Fig. 2) (Perez-Chanona and Trinchieri 2016). Although the value of microbiota-based vaccination remains highly speculative, what is certain is that many new insights will be gained from studying immune responses to commensals in the next several years.

\section{REFERENCES}

Abt MC, Lewis BB, Caballero S, Xiong H, Carter RA, Susac B, Ling L, Leiner I, Pamer EG. 2015. Innate immune defenses mediated by two ILC subsets are critical for 
protection against acute Clostridium difficile infection. Cell Host Microbe 18: 27-37.

Ahern PP, Schiering C, Buonocore S, McGeachy MJ, Cua DJ, Maloy KJ, Powrie F. 2010. Interleukin-23 drives intestinal inflammation through direct activity on T cells. Immunity 33: 279-288.

Atarashi K, Tanoue T, Oshima K, Suda W, Nagano Y, Nishikawa H, Fukuda S, Saito T, Narushima S, Hase K, et al. 2013. Treg induction by a rationally selected mixture of Clostridia strains from the human microbiota. Nature 500: $232-236$

Ayres JS. 2016. Cooperative microbial tolerance behaviors in host-microbiota mutualism. Cell 165: 1323-1331.

Beura LK, Hamilton SE, Bi K, Schenkel JM, Odumade OA, Casey KA, Thompson EA, Fraser KA, Rosato PC, FilaliMouhim A, et al. 2016. Normalizing the environment recapitulates adult human immune traits in laboratory mice. Nature 532: 512-516.

Doria-Rose NA, Joyce MG. 2015. Strategies to guide the antibody affinity maturation process. Curr Opin Virol 11: 137-147.

Hirota K, Duarte JH, Veldhoen M, Hornsby E, Li Y, Cua DJ, Ahlfors H, Wilhelm C, Tolaini M, Menzel U, et al. 2011. Fate mapping of IL-17-producing T cells in inflammatory responses. Nat Immunol 12: 255-263.

Honda K, Littman DR. 2016. The microbiota in adaptive immune homeostasis and disease. Nature 535: 75-84.

Hooper LV, Littman DR, Macpherson AJ. 2012. Interactions between the microbiota and the immune system. Science 336: $1268-1273$.

Howitt MR, Lavoie S, Michaud M, Blum AM, Tran SV, Weinstock JV, Gallini CA, Redding K, Margolskee RF, Osborne LC, et al. 2016. Tuft cells, taste-chemosensory cells, orchestrate parasite type 2 immunity in the gut. Science 351: 1329-1333.

Kau AL, Planer JD, Liu J, Rao S, Yatsunenko T, Trehan I, Manary MJ, Liu TC, Stappenbeck TS, Maleta KM, et al. 2015. Functional characterization of IgA-targeted bacterial taxa from undernourished Malawian children that produce diet-dependent enteropathy. Sci Transl Med 7: 276ra224.

Lee YK, Menezes JS, Umesaki Y, Mazmanian SK. 2011. Proinflammatory T-cell responses to gut microbiota promote experimental autoimmune encephalomyelitis. Proc Natl Acad Sci 108: 4615-4622.

Longman RS, Diehl GE, Victorio DA, Huh JR, Galan C, Miraldi ER, Swaminath A, Bonneau R, Scherl EJ, Littman DR. 2014. $\mathrm{CX}_{3} \mathrm{CR} 1^{+}$mononuclear phagocytes support colitis-associated innate lymphoid cell production of IL22. J Exp Med 211: 1571-1583.

Naik S, Bouladoux N, Linehan JL, Han SJ, Harrison OJ, Wilhelm C, Conlan S, Himmelfarb S, Byrd AL, Deming C, et al. 2015. Commensal-dendritic cell interaction specifies a unique protective skin immune signature. Nature 520: 104-108.

Okada S, Markle JG, Deenick EK, Mele F, Averbuch D, Lagos M, Alzahrani M, Al-Muhsen S, Halwani R, Ma CS, et al. 2015. Immunodeficiencies. Impairment of immunity to Candida and Mycobacterium in humans with bi-allelic RORC mutations. Science 349: 606-613.

Palm NW, de Zoete MR, Cullen TW, Barry NA, Stefanowski J, Hao L, Degnan PH, Hu J, Peter I, Zhang W, et al. 2014. Immunoglobulin A coating identifies colitogenic bacteria in inflammatory bowel disease. Cell 158: 1000-1010.

Pamer EG. 2016. Resurrecting the intestinal microbiota to combat antibiotic-resistant pathogens. Science 352: 535 538.

Perez-Chanona E, Trinchieri G. 2016. The role of microbiota in cancer therapy. Curr Opin Immunol 39: 75-81.

Rangan KJ, Pedicord VA, Wang YC, Kim B, Lu Y, Shaham S, Mucida D, Hang HC. 2016. A secreted bacterial peptidoglycan hydrolase enhances tolerance to enteric pathogens. Science 353: 1434-1437.

Sallusto F. 2016. Heterogeneity of human $\mathrm{CD}^{+}{ }^{+}$T cells against microbes. Annu Rev Immunol 34: 317-334.

Sano T, Huang W, Hall JA, Yang Y, Chen A, Gavzy SJ, Lee JY, Ziel JW, Miraldi ER, Domingos AI, et al. 2015. An IL23R/IL-22 circuit regulates epithelial serum amyloid A to promote local effector Th17 responses. Cell 163: 381393.

Schieber AM, Lee YM, Chang MW, Leblanc M, Collins B, Downes M, Evans RM, Ayres JS. 2015. Disease tolerance mediated by microbiome E. coli involves inflammasome and IGF-1 signaling. Science 350: 558-563.

Sonnenberg GF, Monticelli LA, Elloso MM, Fouser LA, Artis D. 2011. $\mathrm{CD}^{+}$lymphoid tissue-inducer cells promote innate immunity in the gut. Immunity 34: 122-134.

Wu HJ, Ivanov II, Darce J, Hattori K, Shima T, Umesaki Y, Littman DR, Benoist C, Mathis D. 2010. Gut-residing segmented filamentous bacteria drive autoimmune arthritis via T helper 17 cells. Immunity 32: 815-827.

Yang Y, Torchinsky MB, Gobert M, Xiong H, Xu M, Linehan JL, Alonzo F, Ng C, Chen A, Lin X, et al. 2014. Focused specificity of intestinal TH17 cells towards commensal bacterial antigens. Nature 510: 152-156. 


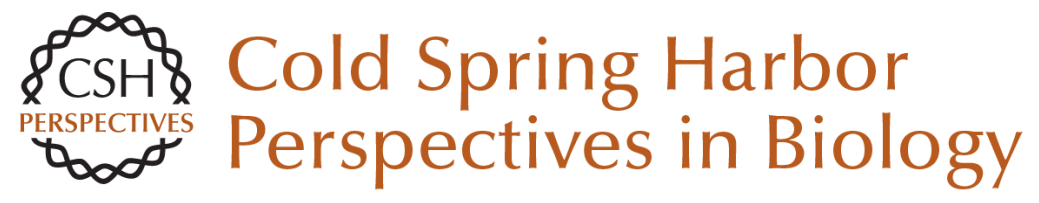

\title{
Do the Microbiota Influence Vaccines and Protective Immunity to Pathogens?: If So, Is There Potential for Efficacious Microbiota-Based Vaccines?
}

\author{
Dan R. Littman
}

Cold Spring Harb Perspect Biol 2018; doi: 10.1101/cshperspect.a029355 originally published online April 21, 2017

\section{Subject Collection Immune Memory and Vaccines: Great Debates}

Is There Natural Killer Cell Memory and Can It Be Harnessed by Vaccination?: Can Natural Killer and CD8 T Cells Switch Jobs?

Christine A. Biron and Marcus Altfeld

Is There Natural Killer Cell Memory and Can It Be Harnessed by Vaccination?: Vaccination Strategies Based on NK Cell and ILC Memory Megan A. Cooper, Todd A. Fehniger and Marco Colonna

Is It Possible to Develop Cancer Vaccines to Neoantigens, What Are the Major Challenges, and How Can These Be Overcome?: Neoantigens as Vaccine Targets for Cancer Haydn T. Kissick

Is It Possible to Develop Cancer Vaccines to Neoantigens, What Are the Major Challenges, and How Can These Be Overcome?: Neoantigens: Nothing New in Spite of the Name

Olivera J. Finn and Hans-Georg Rammensee
Is There Natural Killer Cell Memory and Can It Be Harnessed by Vaccination?: NK Cell Memory and Immunization Strategies against Infectious Diseases and Cancer Joseph C. Sun and Lewis L. Lanier

Is There Natural Killer Cell Memory and Can It Be Harnessed by Vaccination?: Natural Killer Cells in Vaccination

Harold R. Neely, Irina B. Mazo, Carmen Gerlach, et al.

Is It Possible to Develop Cancer Vaccines to Neoantigens, What Are the Major Challenges, and How Can These Be Overcome?: Targeting the Right Antigens in the Right Patients Stephen P. Schoenberger

Which Dengue Vaccine Approach Is the Most Promising, and Should We Be Concerned about Enhanced Disease after Vaccination?: There Is Only One True Winner Scott B. Halstead

For additional articles in this collection, see http://cshperspectives.cshlp.org/cgi/collection/

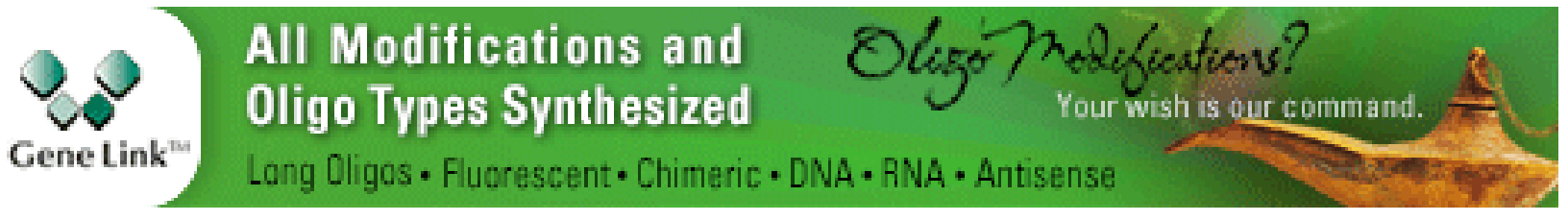


Which Dengue Vaccine Approach Is the Most Promising, and Should We Be Concerned about Enhanced Disease after Vaccination?: The Challenges of a Dengue Vaccine

Gavin Screaton and Juthathip Mongkolsapaya

Which Dengue Vaccine Approach Is the Most Promising, and Should We Be Concerned about Enhanced Disease after Vaccination?: The Path to a Dengue Vaccine: Learning from Human Natural Dengue Infection Studies and Vaccine Trials Aravinda M. de Silva and Eva Harris

Is It Possible to Develop a "Universal" Influenza Virus Vaccine?: Potential for a Universal Influenza Vaccine James E. Crowe, Jr.

Is It Possible to Develop a "Universal" Influenza Virus Vaccine?: Outflanking Antibody Immunodominance on the Road to Universal Influenza Vaccination

Davide Angeletti and Jonathan W. Yewdell
Which Dengue Vaccine Approach Is the Most Promising, and Should We Be Concerned about Enhanced Disease after Vaccination?: Questions Raised by the Development and Implementation of Dengue Vaccines: Example of the Sanofi Pasteur Tetravalent Dengue Vaccine Bruno Guy

Which Dengue Vaccine Approach Is the Most Promising, and Should We Be Concerned about Enhanced Disease after Vaccination?: The Risks of Incomplete Immunity to Dengue Virus Revealed by Vaccination

Stephen S. Whitehead and Kanta Subbarao

Is It Possible to Develop a "Universal" Influenza Virus Vaccine?: Immunogenetic Considerations Underlying B-Cell Biology in the Development of a Pan-Subtype Influenza A Vaccine Targeting the Hemagglutinin Stem Sarah F. Andrews, Barney S. Graham, John R. Mascola, et al.

Is It Possible to Develop a "Universal" Influenza Virus Vaccine?: Potential Target Antigens and Critical Aspects for a Universal Influenza Vaccine Florian Krammer, Adolfo García-Sastre and Peter Palese

For additional articles in this collection, see http://cshperspectives.cshlp.org/cgi/collection/

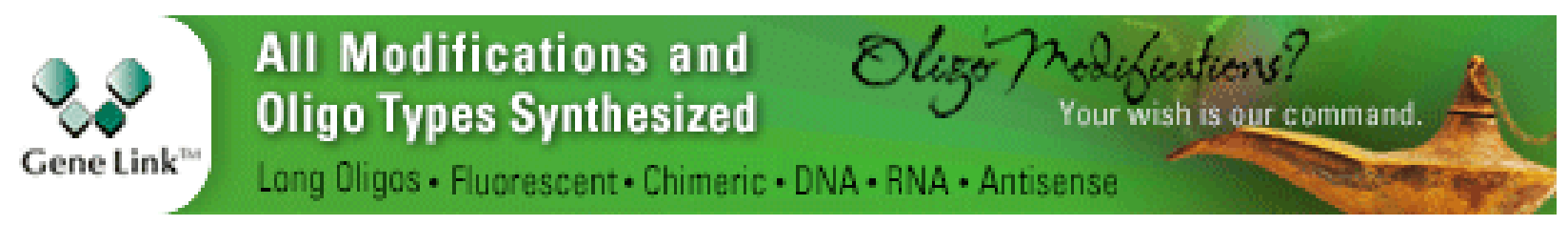

